\title{
ADVANCED DISTRIBUTED LEARNING FOR A GROWING SECURITY COMMUNITY
}

\section{Introduction to ADL}

A number of terms are used to denote the application of information and communication technologies (ICT) in education and training: learning technologies, interactive multimedia instruction, computer-based training, networked learning, elearning, etc. Some of them are more specific than others, and the choice of Advanced Distributed Learning (ADL) as a title and main topic of this issue of Information \& Security was driven by two factors. First, the term ADL originated within the initiative, which is related to military education and training and, thus, it is probably known to regular readers of this journal. Second, the term is well known outside of this community; some associate it with targeted approach to deployment of learning technologies in educational institutions.

Considering the community's attitude to the use of ICT in education in the last decade, it is possible to notice some changes. On the one hand, those who pioneered transformation of traditional education processes to distance learning and training slowed down innovations to evaluate outcomes and identify areas of promising return on investment (ROI). On the other hand, more and more educators are willing to learn how to use ICT in their professional activities and are ready for a try. Both sides agree that particular technologies are useful and effective in certain situations. This is a good starting point. ADL is not seeking to substitute each educational process and get teachers and trainers out of job; it rather creates a spectrum of technologies for learning and training support to make the process efficient, affordable and accessible.

The papers in this special issue discuss variety of applications and technologies and represent views from around the world on the role and perspectives of ADL. Altogether, they form a picture of objectives, achievements, research topics, practical tasks, and thoughts related to ADL.

The papers are grouped in three sections, though there are other connections among them. The first section is focused on the ADL initiative and activities related to or inspired by it at national or international level. The next one contains examples of learning technologies and discussion of the role of technical standards in ensuring 
interoperability among separate applications. Contributors to the last section discuss some cultural and legal aspects of implementing learning technologies and their impact on community.

\section{ADL and multinational collaboration}

This special issue starts with first-hand information from Robert Wisher and J. Dexter Fletcher about ADL in its original and most precise meaning. The authors offer a historical overview of ADL both as a research field and as framework for the introduction of innovative technologies in learning and training, and share their thoughts about future advancements.

The ADL initiative achieved noticeable results in a short timeframe. It united efforts of leading researchers and practitioners in the field of e-learning and set up objectives in order to:

- Prioritize research studies;

- Focus research on achieving practical outcomes;

- Combine isolated technical accomplishments into a common framework.

The international recognition and the success of the ADL framework and approach were driven by several factors, such as:

- Accountability and gradual progress. Together with the challenging goals of providing individualized, high quality and affordable training and education, the project has a stepwise agenda, which is practical and manageable;

- Healthy pragmatics. Although based on awareness of the leading research in the field, the adopted common model and framework capitalized on proven techniques, ready for large-scale deployment;

- Added value. Technologies are targeted at specific audience, tailored for particular pedagogical tasks and recommended in a certain training scenario. This ensures their didactical effectiveness, efficiency, and acceptance;

- Standards for today. Interoperability specifications, produced by the ADL, ensure basic compatibility and interaction among learning technology components leaving space for future advancements.

A realistic view on what is available for large-scale use in meeting challenging goals might have its impact on e-learning community that overcame a period of doubts and instability caused by the crisis in the IT industry.

The ADL topic is caught up by Jannie Barrett who described implementation of the ADL concept within the Partnership for Peace (PfP) initiative and the evolution of bilateral Swiss-USA collaboration into a large multinational project involving NATO 
and Partner countries. The initiators of the project provide leadership and coordinate participation of individuals and organizations in a number of ADL-related activities, including development of an open-source learning management system (LMS) and free learning content. The strategic vision of the PfP Consortium to attain interoperability through education and training ${ }^{1}$ brought to life a pioneering effort aimed at providing affordable learning technologies. The PfP ADL working group, which hosted the project, built up a community of and set up a forum for researchers, learning content developers, instructors and educational administrators from civilian and military educational organizations. The ADL working group activities are arranged around project developments and enriched by sharing experience with experts outside of the group.

The PfP Consortium supported information infrastructure development in Partner countries by supplying equipment necessary to establish collaboration through networking. The first steps towards the PfP LMS and shared content implementation were made at a high time of commercial developments when ideas of open source software and shared learning content were in their infantry.

The state of the art in the PfP ADL is marked by the following achievements:

- A new version of the PfP LMS is on the way, which further develops the idea of simple, reliable and manageable system. It has a modular architecture and is able to run SCORM-conformant courses developed elsewhere. It further supports web-classroom activities and courseware development.

- More than 20 courses were designed and made available for all interested parties. Many of them resulted from a collaborative development process and allied the experience of multiple parties. The courses are in use by training centers, universities and institutes of security studies in NATO and Partner countries and are offered for distance learning, self-study, and as a supporting measure to face-to-face instruction.

- The courses are being transformed into SCORM-conformant format to facilitate their wider dissemination. This would also simplify further collaboration in maintenance and update of the courses. This is especially important for learning content related to current situation, such as in the courses Introduction to NATO and Terrorism and its Implications for Democratic States, to name just two. SCORM packages of the PfP LMS courses may be retrieved for use in a particular educational organization, and then recombined and tailored to its needs.

The next paper contains a detailed description of the course developed in the PfP LMS - English Skills for Staff Officers in Multinational Operations. The authors report on their experience in collaborative design and development of a language- 
learning course, as well as results of a pilot study. They started their work with user needs analysis and adhered to simple solutions to make course appropriate for use in Partner countries. Availability of computers with Internet connection and bandwidth sufficient for large volumes of information, as well as personnel skills for working in a computer environment vary significantly around the world. In some former Partner countries that recently joined NATO, such as Estonia, necessary conditions for information society and extensive use of ICT in everyday practice are already created. Many other countries still have an uneven distribution of available ICT services and low computer and Internet literacy level. At the same time, the countries with less developed technological infrastructure are in a sharp need of language training for successful participation in multinational operations.

The instructors, participating in the project, piloted a course with assistance from the George C. Marshall Center students. The obtained feedback confirmed that primary goals, set up by the creators of the original learning material, where preserved and attained through distance learning. All information that was present in the traditional book-and-tape course was preserved, and efforts were made to make computer-based presentation more interesting, engaging, and cognitively challenging. However, the learning objectives of the course cannot be achieved completely without instructor. Technical achievements may enhance voice recognition; complex semanticprocessing mechanisms may help understand the student's input and generate automatic response. But the real user objective is not to graduate with excellence, but to be able to work in multinational environment, perform professional duties and communicate with people.

The thresholds, beyond which learning technologies lose to humans, are discussed in the next paper. Andrij Ivashchenko and Kateryna Synytsya present a view on the ADL potential to support training of national forces for participation in multinational operations. The need for technological support is justified by several factors, including distributed location of volunteers, variety of their skills and experience, large number of personnel to be trained, complexity in providing sufficient number of qualified instructors for each location, short timeframe for training. The paper examines the whole spectrum of training support that may be provided during the training cycle and identifies specific content and technologies required at each stage. The project is initiated nationally and has a good potential for international collaboration with countries actively participating in multinational operations. The efficiency of the ADL-based training depends on the ability of learning content provider to deliver relevant and authentic experience. Thus, international collaboration in digitizing experience gained during the mission and its transformation into "lessons learned," examples and training assignments would facilitate enhancement of training quality. 
The national perspective of training advancement for personnel taking part in multinational operations is followed by a paper by Walter Christman and Tom Hazard who address a wider issue from international viewpoint. They describe a large multinational initiative on Coalition Information Systems and Operations (CISO) Learning Network. The project is aimed at facilitating interoperability of multinational forces through information and knowledge sharing, community building and establishing learning and training programs and courses. A top-down approach facilitates benefiting from a variety of existing IT environments and techniques and focuses them on the promotion of "cognitive interoperability"-mainly at operational level - through learning, education, and training. Each of the technical components that may be involved - distributed libraries, interactive simulations, distance courses, collaborative tools, knowledge portals, etc. - has its specific features and purpose. As a whole, they are aimed at creating a sustainable, networked learning environment. The potential of technical integration is further discussed in the next section of the volume.

\section{Applications and interoperability issues}

The adoption of learning technologies by educational institutions and training centers is aimed at making learning and training more effective and efficient. Variety of learning content, pedagogical models, didactical strategies, and techniques offer broad opportunities to arrange effective learning. To this purpose, separate software components should be able to interact and exchange information that may be properly interpreted. It should be possible to integrate them into a complex learning environment managing a learning or a training process. Development of interactive multimedia resources for learning is still expensive and time-consuming, so quality learning content is created with a provision of its further reuse. The framework for interoperability and reuse is set up by technical standards and specifications. They specify common structure and format of data shared by several applications and determine interfaces between software components, thus allowing for transfer of information about the learning process among them.

Jeff Krinock discusses the role of technical standards in fostering learning technologies and enhancement of interaction between software components responsible for specific learning activities. The discussion is supported by analysis of an example of what three standards mean for pilot training. The author justifies the need for coordinated efforts to reach necessary synergy. One of the mentioned documents, SCORM, is a widely known product of the ADL initiative. ${ }^{2}$

The discussed standards have different scope; they are applicable to different technical systems that implement different learning models. At the same time, from the viewpoint of just-in-time training, each of the systems provides learning 
environment for a particular learning activity, and their integrated use would be necessary to gain necessary qualification. The coordination of standards would facilitate combination and sharing of information about learning process and learner's knowledge and skills, and in the future would ensure close integration of respective environments for the purposes of learning on demand. Pereira and Law, in a paper presented in this section, give another example of an integrated environment, which supports several types of learning and may benefit from efficient information sharing mechanisms.

The interest to standardization is growing. Countries with highly developed information and telecommunications infrastructure have been closely following and participating in standards and specification development for a number of years. Their interest is driven by both vendors of educational applications, such as learning and learning content management systems, virtual learning environments, authoring tools, etc., learning content providers and users who are responsible for arranging and managing e-learning for students, employees, or individual learners. Others are catching up, driven by the interests of learning content managers, both administrators and local content providers who try to be competitive. The "I\&S Monitor" section of the journal contains a list of organizations involved in standards development and of web sites monitoring news and events in this field.

In a short paper, Kollár, Samuelis and Rajchman share their experience of transforming already developed learning content into the SCORM-compatible format. Despite the availability of SCORM specifications and support from open source software, transformation of the learning content happens to be no easy task. The problem is that besides changes and updates required by technical specifications, it is necessary to change the vision of the learning content purpose.

Many early-developed courses were designed as an electronic copy of an instructional process. Such a course as a product of tutor-centered design reflected lectures presented by the instructor, and thus some fragments supporting "continuum" of the process are embedded here and there. Reusable content should be free of processspecific context, it should allow for recombination and use in different learning situations. On the other hand, successful learning indeed requires context and continuity, so chunks of reusable content should be glued together before being presented to the learner.

The SCORM-conformance of the course opens two opportunities. First, the course may be successfully transferred from one SCORM-conformant LMS to another; thus it will have wider applicability. In this scenario, the learning processes implemented in a course remain untouched, thus there is no need to de-contextualize separate objects. Another opportunity is to start with creation of proper learning objects (small 
to medium size) to maximize their reusability. ${ }^{3}$ These learning objects may be then combined together in multiple ways, with adding missing contextual information to ensure didactical consistency and validity of the resulting courses.

SCORM specifies combination of separate learning objects in a course and their interaction with LMS. It says nothing about the complexity of each object or didactical approach implemented in it. However, due to the lack of convenient authoring tools to create interactive and intelligent applications, the vast majority of courses are focused on presentation and delivery of learning material. The course of this type is designed as a linear sequence of units that correspond to the unique learning path. The paper by Wasana Ngaogate demonstrates that course topics may be sequenced in more than one meaningful way, thus creating multiple learning paths to be selected by a student. Extensively illustrated, the paper presents intuitive interface and simple course authoring procedures.

The next paper by Márcia Pereira and Effie Law addresses didactical issues and discusses a variety of learner-centered activities to enhance learning and training. Each of the described "learning choices" corresponds to some type of activity, implements a particular model of learning and requires specific information processing and knowledge presentation.

The latter two papers do not position themselves in the standards-paved technological streamline; instead they are focused on didactic strategies, which are well known by researchers but still not fully supported by most systems. Although standards for learning technologies are open to innovations, their orientation to the future rather than blessing of the old practices is often ignored. As a result, attempts are made to apply the standards within the traditional framework, which may not bring all their potential benefits.

\section{ADL and Beyond}

This section presents issues related to e-learning in general and to the impact of learning technologies on society. Matt Fawkner and Greta Keremidchieva discuss ethical issues related to plagiarism and incorrect use of information emerging in education and academic research. Although the roots of these issues are not directly related to Internet or mobile communications, outburst of available information aggravated the situation.

The ready availability of huge amount of resources, opinions, judgments, facts, statistics, illustrative materials on the one hand, gives enough food for thought, but on the other, causes a stress. It may be related to a fear to miss the most important point, inability to determine one's own position or to generalize and present different viewpoints in a balanced way. Current update rate and information volumes require 
more efficient information processing. Skills to sort, catalogue and store information in a systematic way, and to find the source of certain information, are becoming critical.

Information browsing is a typical way of handling secondary sources. The global network and search engines cannot guarantee that the source will be available in the future, so without personal notes some sources may be lost not only for reading, but for referencing. Sometimes people are unable to separate their own conclusions from ideas fished during information browsing. It is interesting that not only the speed of reading, but also lack of rich visual and tactile information facilitate forgetting a source. People can no longer recall that some phrase was from a "large green shabby book."

The authors identify unintended breaches, caused by insufficient skills of using information and limited awareness of information ethics, and conscious information distortion - falsification of assessment results, corruption or change of information, use of forbidden sources or help from others, etc. In the first case, technologies may help bridge the gap by distribution of information and best practices through popular web sites and learning portals, thus raising awareness in the community. In the latter case, technological support is necessary for information security maintenance, authenticity and access control, uncovering fraud, etc. Intelligent information technologies are able to find text fragments documents in a sample that are copied from some known source. Moreover, they are also able to reveal semantic equivalence of fragments, including those presented in different languages, and to determine whether a style of the fragment corresponds to the general style of a particular author. Most of these technologies are used for special purposes, they are resource demanding, expensive and usually require some preliminary tuning to raise reliability. Their simple analogues are not as precise, reliable or smart, but are available for educational purposes. ${ }^{4}$

Information security issues are discussed in the paper contributed by Konstantin Arkhipov and Vasiliy Ovodkov. The authors interpret the concept of security in a wide sense, and consider technologies for information security, as well as expectations and perception of security by a user of learning technology system. Besides traditional methods of data protection and ensuring information integrity, its secure storage and transfer, the authors draw the reader's attention to techniques that take into account specifics of information content and representation.

From the viewpoint of a participant in distance learning, two aspects of security are offered for consideration. The first is related to one's perception of security as ability of a system to preserve data confidentiality (contact information, learning results), to ensure reliable information transfer and results validity (in case of distance testing, 
document exchange), and to grant certain rights for learning control. As well as other features, the last one is important not only for the instructor but also for a learner, especially an adult learner. The other aspect is related to the influence considered from a range of special information presentation and structuring to facilitate desired opinion formation among the users - up to purposeful zombying. As in many other cases, this problem is not specific to distance learning, but is of importance due to public availability of technologies allowing to reach wide international audiences.

Information security issues for all fields of human activities are recently attracting close attention. According to the Information Week research, ${ }^{5} 10$ percent of the IT spending in education is expected to relate to security issues.

The concluding paper in this issue by Ulrich Gysel and Jeff Krinock focuses on situations, in which human-based apprenticeship and tutoring might be the best solution regardless of e-learning progress. The authors consider the use of computers to support learning, education, and training in the wider context of the general impact of technologies on communities and the transformation of educational processes in society. Confirming the positive effect of learning technologies on individual outcomes due to adaptation of learning and training to personal needs, expectations and requirements, the authors invite readers to shift their attention from short-term individual results to the long-term impact on community.

Humankind is moving towards information society where information technologies occupy a leading place, change needs and habits of people (to a certain extent), and put their everyday life in dependence of technological infrastructure. Adoption of IT in many areas, such as document processing or trade, changed the form of processed information but not the essence of work. It is expected that in education, IT will be able to perform more important role and to take more responsibilities. For this purpose, educational processes, roles and interaction between instructor and learner should be transformed; the final success depends on society's readiness to accept these transformations and to integrate them into educational traditions and culture formed in centuries.

This special issue of Information \& Security is edited by Dr. Kateryna Synytsya, CoChair of the ADL Working Group of the PfP Consortium of Defense Academies and Security Studies Institutes. Jannie Barrett's article in this volume presents the activities of the ADL Working Group. Most contributors are members of that group. Certainly, the journal reflects thinking, concepts and experience from the collaboration of a few dozen people in the last five years or so. Therefore, to remedy potential biases, the last section of this journal issue directs the reader to additional ADL and related resources, that are readily available on the Internet and accessible free of charge. The selection was made by the Ukrainian CDT (Cooperative 
Development Team) based at the International Research and Training Center for Information Technologies and Systems, Kyiv, Ukraine. ${ }^{6}$

Information \& Security

\section{References:}

1 Homepage of the Partnership for Peace Consortium of Defense Academies and Security Studies Institutes, <www.pfpconsortium.org> (9 May 2004).

2 Advanced Distributed Learning website, <www.adlnet.org> (9 May 2004).

3 Douglas Hamilton, "Creating Reusable Content: A Practitioner's Observations," Learning Technology newsletter 6, 2 (April 2004): 6-8, <lttf.ieee.org> (9 May 2004).

4 Plagiarism and the Internet, 2001 Workshop report, <www.oucs.ox.ac.uk/ltg/reports/ plag.shtml> (9 May 2004).

5 HPAA information security: The Programmatic Approach and Execution Plan (Columbia, MD: Network Security Consulting, September 2003), <www.vahimss.org/ data/presentations/20030912.pdf> (9 May 2004).

6 Additional information on the IRTC is available at http://www.dlab.kiev.ua/ (9 May 2004). 